\title{
Infrastructure costs and benefits of European high-speed rail
}

\author{
Nedžad Branković, Aida Kalem \\ University of Sarajevo, Faculty of Traffic and Communications, Zmaja od Bosne 8, Sarajevo 71000, Bosnia and Herzegovina
}

\begin{abstract}
The development of new technologies has significantly influenced railways modernization and has caused the appearance of high-speed rail which represents a safe, comfortable, and ecologically sustainable way of transportation. The high-speed rail presents a big step in a relation to conventional railways, where the biggest difference is speed which even entails a change of other organizational and operational parameters, better utilization of trains, higher performance of manpower, and better service to users. That is visible in many cities around the world where high-speed trains are used by billions of users. In the EU there is no unique high-speed railway network, besides that in many EU member countries various operational models are applied. The future of the high-speed railways market depends on political, economical, and technical factors and challenges as high infrastructure costs, various rates of return on investment, and the negative effects of economic crises. The main objective of the paper is to analyze infrastructure costs of high-speed rail in Europe and benefits such as time savings, higher reliability, comfort, safety, reducing pollution, and the release of capacity in the conventional rail network, roads, and airport infrastructure.
\end{abstract}

Keywords: high-speed rail, Europe, infrastructure, costs, benefits

\section{Introduction}

The most comprehensive definition of an high-speed rail is given in the EU Directive 2008/57/EC for interoperability, that high-speed trains define as trains that have to be constructed to ensure safe and undisturbed travel during $250 \mathrm{~km} / \mathrm{h}$ speed on a railway which is specially built for high speeds and speeds above $300 \mathrm{~km} / \mathrm{h}$ in suitable circumstances and also $200 \mathrm{~km} / \mathrm{h}$ speeds on existing railways which are upgraded for that speed. A high-speed railway represents a new way of transportation that spreads rapidly, and it is also called "the future way of transportation". Nowadays, a large number of countries in the world have high-speed railways in function, build new or are upgrading and reconstructing existing railways because they foresee stimulus for the development of their countries. The biggest high-speed railways systems have China, France, Italy, Germany, Spain and Japan. The first high-speed railway in the world has been built in Japan in 1964 for the Olympic games. In Europe first HSR has been built in Italy in 1977, then in France in 1981, and in Spain in 1992 [1]. In the last 30 years system of HSR made its highest impact and today it is used by billions of passengers by using an ecologically acceptable vehicle.

The impact of HSR on an existing transportation way on a market between cities is unavoidable [2]. The success of HSR in the transportation market depends on transportation time and the performances of other modes of transport. By offering high-speed transportation and short time traveling, the system is competitive to certain airlines and other modes of transport. On short distances, in the scope of flexibility, HSR hardly can be competitive with cars. But on long distances advantage has air traffic. The competition between air traffic and HSR can occur on a route of 400 and $800 \mathrm{~km}$ distances [3]. Therefore, it is an obvious advantage of HSR on other modes of transport on a medium distance route.

The railways are the usually dominant way of transport on routes that time of journey is less than 3,5 hours. However, a 4-5 hour railway journey can also be attractive to passengers if airport access times to and from airports, as well as border pass processing times at airports, are high. Benefits that high-speed railways are offering such as shorter travel time and increased level of service (higher operational frequencies and improved travel conditions) lead to changes in the modal share of the route and generate new demand. According to the data presented by Givorni, the comparison before and after the introduction of the high-speed railway is significant. The introduction of the French Train a Grande Vitesse (TGV) Paris-Lyon line resulted in a loss of market share for aircraft by $24 \%$ and a reduction in the share for cars by $8 \%[4]$.

Published: 30 October 2021

Corresponding author: Aida Kalem (aida.kalem@fsk.unsa.ba)

(c) 2021 The Authors. This work is licensed under a Creative Commons Attribution 4.0 International License. 
The main problem of high-speed railways is not technological but in economic nature, which is reflected in the very high costs of infrastructure construction. On corridors with an insufficient number of passengers or with low traffic density, costs per passenger are extremely high, which do not provide financial stability and economic justification. According to the relevant reference value, a high-speed railway ideally should travel nine million passengers per year for it to be successful [5]. From the investment in the infrastructure of high-speed railways and during their use all of society has benefits, which are reflected in a greater reduction in travel time as well as in a high level of safety and comfort. Besides that, road networks, conventional rail networks and airports are being relieved. In addition, with high-speed railway strengthening of the socio-economic dynamic and revitalization of less developed urban areas next to the stations is visible.

The paper reviews and analyzes the condition of the high-speed rail in EU states, such as in France, Germany, Spain and Italy with a focus on their economic, social and environmental effects. This paper is organized as follows. Section 2. provides an overview of the development of high-speed rail in Europe with the length of the network built in selected European countries till 2019. Section 3 contains an analysis of the cost of building high-speed rail across Europe. In section 4. are described the economic and social benefits of high-speed railways, such as their impact on regional development, tourism, travel time savings, environmental advantages, increase of safety and reliability. Finally, section 5. contains final concluding remarks and a discussion for possibilities of future research.

\section{Development of high-speed rail in Europe}

The initial development of high-speed railways is related to the late ' $70 \mathrm{~s}$ and gas crises. When Europe faced energy dependence and threats in terms of mobility, several countries decided to develop a safe, fast, comfortable and environmentally friendly mode of transport that does not depend on fossil fuels. Generally, in the initial phase, the high-speed railway network has been developing on the National level. In 1977., Italy was the first European country with high-speed railways, the railway line from Florence to Rome was put into operation [6]. After Italy, France began to establish its high-speed trains - "Trains à Grande Vitesse". In the early 1990s, the first high-speed lines were opened in Germany, where high-speed trains "Intercity Express" (ICE) has operated. In Spain, the high-speed rail service "Alta Velocidad Español a" (AVE) began in the year of 1992 [7].

The general development of the high-speed railway network in Europe between 1985. and 2013. grew exponentially, initially from two countries to become a relatively widespread transport today. With the establishment of the Trans - European Transport Network (TEN-T) in the early 1990s, the EU began to provide special support to European railway projects, including high-speed railway projects. Figure 1 . shows the development of the high-speed railway network in the EU, which has spread 9100 kilometers till the end of 2019. It is planned that within the Trans - European transport network high-speed railways spread to more than 30000 $\mathrm{km}$ by 2030 [8].

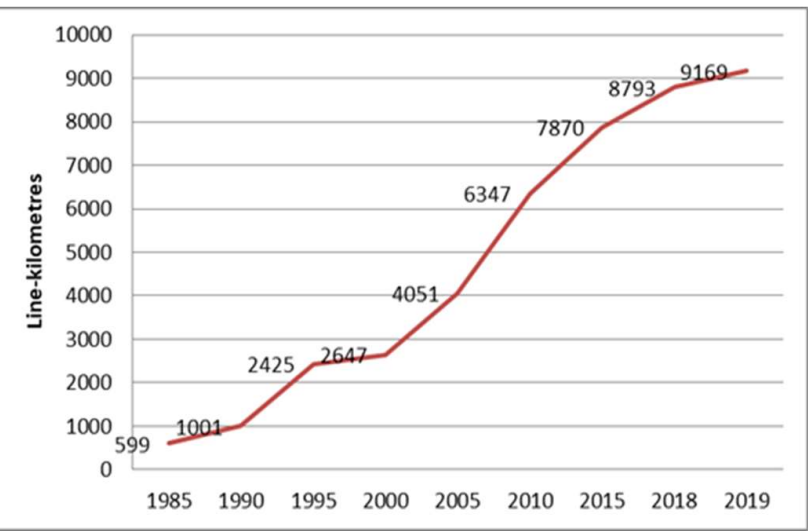

Figure 1. Development of a high-speed railway network in Europe [9]

Figure 2. provides an overview of the length in kilometers of high-speed railway routes in selected European countries in 2019. Spain was the country with the longest high-speed railway, with a total length of 3,297 kilometers. After that, France and Germany had the longest high-speed railways among these countries, with 2,734 and 1,571 kilometers [9]. Austria recorded the shortest high-speed railway line among countries, with a total length of 67 kilometers.

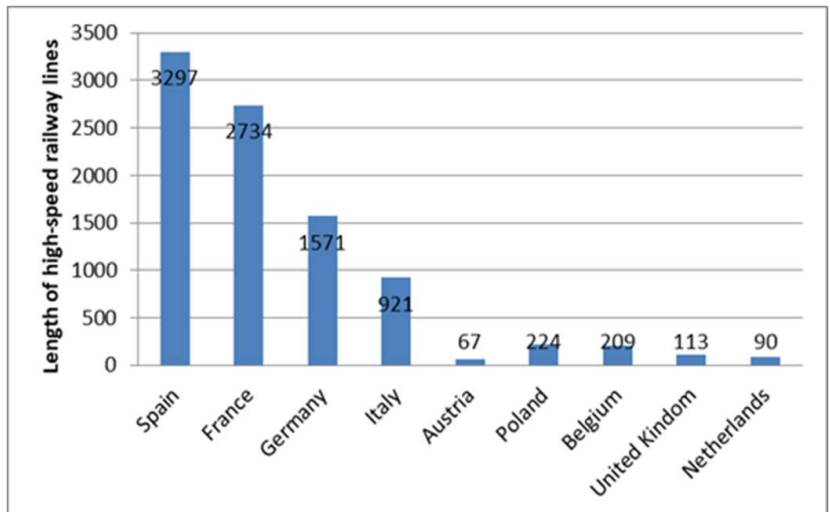

Figure 2. The total length of high-speed railways in use in selected European countries in 2019 (in kilometers) [9]

In Spain and France distances between cities are ideal for high-speed railways. In Spain, the largest city, Madrid 
is located in the center of the country and other important cities are generally on the coast or near the coast, $400-$ $600 \mathrm{~km}$ away. In France, most trips are to and from Paris, then eight of the nine other major cities are more than 400 $\mathrm{km}$ away from Paris, and all distances are within $800 \mathrm{~km}$ except Nice. France has high-speed railway lines to United Kindom (Eurostar), Belgium, Netherlands, Germany (Thalys) and Switzerland, Italy and Spain (TGV). In Germany and Italy, there is a certain number of cities where the range of distances between cities is ideal for a high-speed railway to be competitive, but many other cities are close enough that high-speed railways offer a minor advantage. The British high-speed railway line connects via the Channel Tunnel to the French high-speed railway network, connecting London with Paris, Lille, Brussels and similar cities located on the high-speed railway line in France, Belgium, or the Netherlands. Nowadays, HSR services are provided in many other EU member countries with various maximum speed limits [10], such as in Portugal, Belgium, Netherlands, Sweden, Finland, Poland and Austria.

The problem with the HSR market in Europe is that there is no unique European HSR network. Instead of that various operational models are existing in various EU member countries with different standards and technologies. Four different HSR exploitation models are identified. The first model, also known as the exclusive exploitation model is related to the Japanese Shinkansen, where HSR infrastructure is divided from conventional railway infrastructure. In the EU, three models are in use such as high-speed mixed model, mixed conventional model and fully mixed model [11]. The high-speed mixed model defines that HSR trains use new custom-made railway tracks for high-speed trains or use upgraded tracks on conventional railways. This model match to the French model, whose TGV trains are in traffic, mainly on new railway tracks, but also on re-electrified tracks of conventional lines in areas where duplication was not practical. A fully mixed model allows maximum flexibility. In this model, high-speed and conventional trains (at appropriate speeds) can run on any infrastructure network. An example of this model is the German ICE trains and in Italy the Rome-Florence line, where occasionally high-speed trains use upgraded conventional lines. A mixed conventional model is used in Spain, where some conventional trains can use high-speed railways [12]. The exclusive exploitation model and mixed highspeed models allow more intensive use of high-speed railway infrastructure, while other models must take into account that slower trains use more sections over time and reduce the ability to provide high-speed railway services, except for sections with more railway tracks.

Despite the uneven development of the HSR network and the presence of various operating models since they appeared, the number of passengers who opted for this way of transport is constantly growing, with roughly 15 billion passenger-kilometers in 1990. In 2016 demand has reached more than 124 billion passenger-kilometers [13][14] and the growth trend is continued, in 2017 that number reached 127 billion passenger-kilometers.

\section{Overview of the high-speed rail infrastructure costs}

HSR infrastructure is relatively expensive. Construction costs depend on the characteristics of the railway and equipment. The construction of new infrastructure requires special attention because it is necessary to remove all technical restrictions (railway crossings, frequent stops, sharp curves that are unsuitable for higher speeds, new signaling mechanisms, etc.) that can limit commercial speed below 250-300 km/h [15]. The construction of new HSR infrastructure includes three main types of costs: planning costs and land costs, infrastructure construction costs and superstructure costs [16]. The time required for planning and technical design of HSR lines varies greatly from project to project, depending on their specific legal and administrative arrangements. In some projects, where there are no legal obstacles, effective contractual procedures and appropriate political pressure, the planning period may last less than a year, while in other cases - especially when there are legal conflicts in the expropriation of the land or other issues of public interest - the period planning can be delayed up to 20 years. Analyzes of the development of HSR indicate that costs have varied over time in different projects. The report of the International Transport Forum states that the highest costs were found in Germany, Italy and Belgium, and the lowest in Spain and France [17]. The average cost of construction of HSR lines in France and Spain in 2005. ranged from $€ 5.5$ up to $€ 22.0$ million per kilometer, and in 2017 . from $€ 9.7$ up to $€ 24.9$ million.

In Germany, the cost of construction of HSR lines is higher because the lines run through densely populated areas and include tunnels (in 2005. ranged from $€ 15.0$ up to $€ 28.8$ million per kilometer and in 2017 . from $€ 17.7$ up to $€ 34.1$ million) [18]. It can be observed that these costs show a growth trend. The construction of the ParisLyon HSR in 1981. required an investment of 4.7 million EUR per kilometer [9], and the TGV Méditerranée section opened in 2001 costs were 12.9 million EUR per kilometer. There is a significant range in the cost of HSR infrastructure from country to country, from line to line (as shown in table 1.). Variations are mainly attributed to the terrain along the route, whether it is necessary to build bridges and tunnels; whether a special line was built to the center of the city; and the share of densely populated areas through which the line passes, which in addition to bridges and tunnels means high land costs. 
Table 1. The construction cost of HSR in Italy and Spain (in millions of euros per kilometer) [19]

\begin{tabular}{|c|l|c|l|}
\hline \multirow{5}{*}{ Country } & Section & Cost $(\mathrm{M} € / \mathrm{km})$ & Line description \\
\hline \multirow{5}{*}{ Italy } & Turin - Milan & 54 & Plain line in an agricultural area, along the highway \\
\cline { 2 - 5 } & Bologna - Florence & 31 & Plain line in an agricultural area, along the highway \\
\cline { 2 - 5 } & Rome - Naples & 68 & Semi-continuous tunnel in complex rock \\
\hline \multirow{5}{*}{ Spain } & Madrid-Andalucía & 24 & Plain/hilly line in an agricultural area \\
\cline { 2 - 5 } & Madrid-Barcelona & 8.9 & Plain line in an agricultural area, along the highway \\
\cline { 2 - 5 } & Madrid- Levante & 10.8 & Plain/hilly line in an agricultural area \\
\cline { 2 - 5 } & Madrid-Valladolid & 9.2 & $\begin{array}{l}\text { Semi-continuous tunnel in complex rock halfway/Plain line in } \\
\text { agricultural areas halfway }\end{array}$ \\
\hline
\end{tabular}

The construction of routes with tunnels or viaducts is considered to be four to six times more expensive per kilometer than construction over flat land. Considering the diversity of locations and types of systems, it is not surprising that these costs vary from below $€ 10$ million per kilometer of the route (LGV South-East) to over $€ 100$ million per km (British HSR1 line) [19].

The construction cost of completely new infrastructure can be significantly higher compared to upgrading a conventional railway [20]. Estimates for the $155 \mathrm{~km}$ section from Venice to Trieste indicate a cost of $€ 7.5$ billion for the new $300 \mathrm{~km} / \mathrm{h}$ HSR line (i.e. $€ 48.3$ million per $\mathrm{km}$ ), compared to $€ 1.8$ billion for the upgrade of the conventional railway (i.e. EUR 11.6 million per $\mathrm{km}$ ) [21]. Lower construction costs were recorded in those projects that combined conventional railways with tracks of HSR. The reason that is supporting this strategy is to avoid the high costs of land expropriation which makes the construction of HSR through cities extremely expensive and therefore the use of conventional railways for this purpose significantly reduces these costs.

From 2000. to 2017. the EU invested $€ 23.7$ billion in grants to co-finance investments in HSR infrastructure, as well as $€ 4.4$ billion in support for the deployment of ERTMS in HSR [13]. This unique system has been developed and co-financed by the EU and aims to create an interoperable HSR network. The EU invests in railway and HSR, mainly through its European Structures and Investment Funds (ESI), in particular the European Regional Development Fund (ERDF) and the Cohesion Fund. EU co-finances studies as well as infrastructure works, both on new HSR lines and on construction on existing conventional railways, to adapt to high-speed operations.

\section{Benefits of high-speed rail}

From its appearance until today, the development of HSR has been on a constant rise. This success is due to its transport efficiency, high level of safety and security, high level of availability and reliability, and its environmental friendliness. HSR has numerous advantages over other modes of transport such as air, conventional rail and car for medium and long distance and in terms of sustainability it is the most efficient mode of transport. In addition, it is characterized by speed, reliability, comfort and safety. All these advantages enabled HSR to compete with other modes of transport and have made a modal shift possible.

High-speed railway lines are a generator of economic growth and development. European countries have recognized their potential. State railways in most EU countries have been investing billions for the last decades in achieving average train speeds of around 200 kilometers per hour. Time is a key factor today, and highspeed railways are increasing speeds day by day, reducing travel time and thus being able to compete with other modes of transport in the time and price segment. Climate changes and the consequences of the pandemic COVID19 are likely to encourage more intensive use of public transport and the shift to high-speed trains for mediumdistances (around 1,000 km), which has proven to be the 
most sustainable transport vehicle. There are many ways in which high-speed rail systems can offer benefits to urban centers, regions but also small towns on the route. The economic and social benefits of high-speed rail are presented below.

\subsection{Economic benefits of high-speed rail}

Transport infrastructure has a positive impact on economic growth, trade, resource flow, employment and other aspects. The aim of planning and construction of an HSR is reflected in the strengthening of interregional and inner-regional relations. Several studies have found positive statistical relations between the area's connection to the HSR line and regional development [22]. The main direct impact of HSR on the region is to create or improve the accessibility of the area, place and city in the region to change its economic and geo-traffic position. The HSR network increases the concentration of economic activities in large cities, such as London, Paris and other metropolises [23].

Also, HSR has shown a positive impact on tourism, like many airports, located far from the city center, and HSR can run right to the city centers, stations are located near cultural facilities, restaurants, hotels and shopping centers. The cities like Madrid, Cordoba, Toledo, Seville, and Barcelona, which have HSR lines are more accessible and much easier for tourists to visit. The results have shown that the construction of an HSR in Spain has had a positive impact on foreign tourism (especially on revenues from foreign tourism) [24]. Empirical analysis of data on the impact of HSR shows that the advantages of HSR, such as savings in travel time, safety, comfort, accuracy and train frequency, are significant in terms of increased business activity and productivity. For example, on the Madrid - Barcelona section, an assessment was made of the economic benefits of introducing a faster railway line and it was found that an HSR increases labor productivity and economic benefits [25]. The construction of the HSR enables sustainable development, allows the rapid flow of passengers and goods with a significant improvement of railway transport capacity, which has a positive impact on the economic development of the area along the route.

\subsection{Social benefits of high-speed rail}

The investments in HSR infrastructure and their use bring benefit to a whole society, as it saves passengers time and a high level of safety, protection and comfort during traveling. This relieves the capacities of the congested road network and the network of the conventional railway system and airports [26]. They can alleviate congested road and air infrastructure, especially for short and medium distances. They are also more resistant to weather conditions than road and air transport, and can therefore continue to provide services in conditions that would make a road, and especially air operations impossible. Investing in HSR reduces the net environmental impact of transport and contributes to regional development, and helps revitalization of less developed urban areas near stations. Therefore, the social benefits of HSR will be explained in more detail below.

Time-saving - One of the main factors when considering the competition among other modes of transportation is savings in total travel time. The timesaving benefits will depend on the current door-to-door travel time for the available modes of transport compared to the difference achieved through HSR.

Table 2. Door-to-door travel analysis on selected HSR routes [13]

\begin{tabular}{|c|c|c|c|c|c|c|c|c|}
\hline & \multicolumn{2}{|c|}{$\begin{array}{l}\text { MADRID, Puerta del } \\
\text { Sol - BARCELONA, } \\
\text { Plaça de Catalunya }\end{array}$} & \multicolumn{2}{|c|}{$\begin{array}{l}\text { ROME, Piazza del } \\
\text { Campidoglio - } \\
\text { MILAN, Piazza del } \\
\text { Duomo }\end{array}$} & \multicolumn{2}{|c|}{$\begin{array}{c}\text { BERLIN, Potsdamer } \\
\text { Platz - MUNICH, } \\
\text { Marienplatz }\end{array}$} & \multicolumn{2}{|c|}{$\begin{array}{c}\text { PARIS, Place de la } \\
\text { Concorde - } \\
\text { STRASBOURG, Place } \\
\text { du Château }\end{array}$} \\
\hline Distance & \multicolumn{2}{|c|}{$607-698 \mathrm{~km}$} & \multicolumn{2}{|c|}{$572-661 \mathrm{~km}$} & \multicolumn{2}{|c|}{$587-654 \mathrm{~km}$} & \multicolumn{2}{|c|}{$466-548 \mathrm{~km}$} \\
\hline $\begin{array}{l}\text { Mode of } \\
\text { transport }\end{array}$ & Time & $\begin{array}{l}\text { Price } \\
\text { (euro) }\end{array}$ & Time & $\begin{array}{l}\text { Price } \\
\text { (euro) }\end{array}$ & Time & $\begin{array}{l}\text { Price } \\
\text { (euro) }\end{array}$ & Time & $\begin{array}{l}\text { Price } \\
\text { (euro) }\end{array}$ \\
\hline Car & $\begin{array}{c}10: 40- \\
18: 20\end{array}$ & $138-190$ & $\begin{array}{c}10: 40- \\
18: 40\end{array}$ & 180 & $\begin{array}{c}10: 00- \\
16: 40\end{array}$ & $95-142$ & $8: 40-12: 20$ & $44-79$ \\
\hline Air & $6: 30-8: 00$ & $227-253$ & $6: 30-7: 00$ & 140 & $6: 30-8: 00$ & 146 & $\mathrm{~N} / \mathrm{A}$ & N/A \\
\hline Coach & $\begin{array}{c}16: 20- \\
18: 00\end{array}$ & $36-49$ & $\begin{array}{l}15: 00- \\
21: 00\end{array}$ & 40 & $\begin{array}{l}17: 00- \\
23: 00\end{array}$ & $45-79$ & $\begin{array}{l}13: 00- \\
22: 40\end{array}$ & $33-55$ \\
\hline Conventional rail & $\begin{array}{c}11: 30- \\
12: 00\end{array}$ & $124-128$ & $\begin{array}{l}9: 00- \\
23: 00\end{array}$ & $61-103$ & N/A & N/A & N/A & N/A \\
\hline High-speed rail & 6:00-8:20 & $159-181$ & $6: 50-9: 00$ & $23-205$ & $8: 30-10: 30$ & 66 & $5: 10-5: 30$ & $158-165$ \\
\hline
\end{tabular}


Table 2. shows the time and price of travel for different modes of transport on selected lines. With shorter travel times, HSR can offer passengers a higher level of comfort than other modes such as conventional railway, air, or bus transport. A special report from the European Court of Auditors analyzed the early and compared door-to-door travel times, prices and number of connections between the HSR and its competitors (air transport, conventional railway and road transport). Total travel time, price and efficient regular lines are factors that could allow HSR to increase its market share. Estimation of time travel, priceand more connections suggests that HSR has advantages compared to competitive ways of transportation (air traffic, conventional railways, and road transport).

Improving safety In terms of safety, according to the deaths of passengers per billion passenger-kilometers, HSR is considered to be the safest mode of long-distance transport, compared to cars or planes [26]. The reason for this is the fact that the HSR system was designed to reduce the possibility of accidents. The routes are completely separate and have built-in safety features. Safety costs mean higher costs during construction and maintenance.

Reduction of congestion - The benefits of diverting users from other transport modes to HSR result in a reduction in externalities - congestion, accidents and emissions. Congestions on the existing railway, road and air systems give priority to HSR, which has a larger transportation capacity and not just for fast intercity trains even for suburban and regional passenger trains and freight transport [18]. Most European corridors have more than 25 services per day, and this is an advantage that air competitors rarely have due to airport capacity limitations and air traffic congestion.

Improving reliability - The biggest problem faced by public transport in any country is the unreliability of time travel and waiting for transport. HSR has improved reliability, by avoiding congestion and delays, unlike highways and traditional railways [27]. With less delays than other forms of land or air transport, HSR trains can operate more frequently than conventional public transport systems. In addition, HSR trains operate independently of other transport modes in almost all weather conditions.

Reducing pollution - The HSR is environmentally friendly and has far lower greenhouse gas emissions than other modes of transport. Greenhouse gas emission calculations related to the movement of vehicles in five different modes of transport (airplane, conventional train, car, bus and HSR) for the Madrid-Barcelona route assuming low, average and maximum occupancy in each transport mode are shown in Figure 3. It has been found that HSR transport is more efficient than competitive modes of transport, in terms of greenhouse gas emissions. It is clear that high-speed rail has significantly lower levels of greenhouse gas emissions compared to other modes of transport. Among other advantages such as comfort, speed, safety can compete with other modes of transport and reduce social energy consumption and emissions.

\section{Emissions ( $\left.\mathrm{gCO}_{2} / \mathrm{pkm}\right)$}

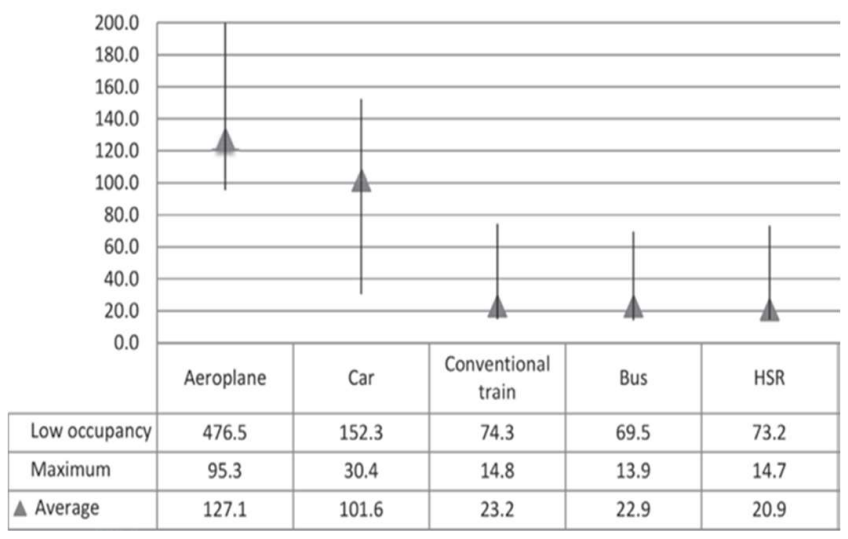

* average occupancy is 75 percent in an airplane, 30 percent in a car, 64 percent in a conventional train, 61 percent in a bus and 70 percent in HSR

Figure 3. Greenhouse gas emissions for the Madrid-Barcelona route [28]

In many countries, there are already laws and policies that require businesses and consumers to reduce their emissions to control pollution. Although the idea of sustainable transport systems has been present in Europe for a long time, it was not until 2008 that the European Commission introduced a specific "environmental transport package", which contained several provisions aimed at internalizing external costs, which were later developed in more details in the White Paper in 2011. Many of these initiatives were implicitly based on the idea that necessary to perform modal division between passengers and cargo from less 'environmentally friendly' modes (road and air transport) toward "greener" (such as railway and maritime transport) modes of transport.

\section{Conclusion}

High-speed railways have truly revolutionized sustainable mobility by allowing a significant increase in the speed and frequency of travel between major European cities. HSR infrastructure represents the Union's immense capacity for technological innovation and the vitality of a European industry that is constantly developing new systems, especially in terms of new fleets. Reduced time travel, a higher level of passenger comfort and a low environmental impact allow HSR to compete and complement with road and air travels, helping to achieve sustainable mobility at the European level. Several economic and cultural centers in Europe already 
have trains running at speeds of $300 \mathrm{~km} / \mathrm{h}$. These centers are major European cities such as London, Paris, Brussels, Frankfurt, Amsterdam, Barcelona, Madrid, Rome and Milan. This success also demonstrates an outstanding ability to innovate, enabling the creation of competitive and interoperable systems of real technological excellence that support the development of the EU economy. A key priority is the development of further connections, such as the Trans-European Transport Network (TEN-T). With the completion of these projects, the Union and its citizens should have an HSR network that will allow its users to travel in conditions of improved comfort and safety while reducing environmental impact. Therefore, soon HSR tends to become a transport system that closely meets the requirements of its users, which is fast and intelligent and most importantly has a minimal impact on the environment.

\section{References}

[1] B. Feigenbaum, "High-Speed Rail in Europe and Asia: Lessons for the United States," Policy Study 418, no. May, p. 46, 2013,

[2] A. López-Pita and F. Robusté, "Impact of High-Speed Lines in Relation to Very High Frequency Air Services," J. Public Transp., vol. 8, no. 2, pp. 17-35, 2005, doi: 10.5038/2375-0901.8.2.2.

[3] T. D'Alfonso, C. Jiang, and V. Bracaglia, "Air transport and high-speed rail competition: Environmental implications and mitigation strategies," Transp. Res. Part A Policy Pract., vol. 92, pp. 261-276, 2016, doi: 10.1016/j.tra.2016.06.009.

[4] M. Givoni, "Development and impact of the modern high-speed train: A review," Transp. Rev., vol. 26, no. 5, pp. 593-611, 2006, doi: 10.1080/01441640600589319.

[5] G. De Rus and C. Nash, "In what circumstances is investment in High Speed Rail worthwhile?," Transport, no. June 2014, 2007,

[6] C. Desmaris and F. Croccolo, "The HSR competition in Italy: How are the regulatory design and practices concerned?," Res. Transp. Econ., vol. 69, pp. 290-299, 2018, doi: 10.1016/j.retrec.2018.05.004.

[7] N. Buier, "The Second Coming of Rail: The Spanish High-Speed Rail-Finance Complex," Antipode, vol. 52, no. 6, pp. 1603-1623, 2020, doi: 10.1111/anti.12672.

[8] M. Prussi and L. Lonza, "Passenger aviation and high speed rail: A comparison of emissions profiles on selected european routes," J. Adv. Transp., vol. 2018, 2018, doi: 10.1155/2018/6205714.

[9] EC, EU transport in figures Statistical pocketbook 2020. 2020.

[10] E. Parliament, "High-Speed Rail in the World," no. September, p. 3, 2015,

[11] H. Almujibah and J. Preston, "The total social costs of constructing and operating a high-speed rail line using a case study of the riyadh-dammam corridor, Saudi Arabia," Front. Built Environ., vol. 5, no. June, pp. 118, 2019, doi: 10.3389/fbuil.2019.00079.

[12] C. Blanquart and M. Koning, "The local economic impacts of high-speed railways: theories and facts," Eur. Transp. Res. Rev., vol. 9, no. 2, 2017, doi: 10.1007/s12544-017-0233-0.

[13] M. Bode et al., "Special Report: High speed rail," vol. 287, no. 19, 2018, [Online]. Available: https:/www.eca.europa.eu/Lists/ECADocuments/SR18 _19/SR_HIGH_SPEED_RAIL_EN.pdf.

[14] A. Bleijenberg, "Air2Rail," no. March, pp. 1-43, 2020.

[15] J. Campos, "A review of HSR experiences around the world Chapter 1 : A review of HSR experiences around the world," no. June 2014, 2007.

[16] E. M. Belal, A. A. Khalil, and K. M. El-Dash, "Economic investigation for building a high-speed rail in developing countries: The case of Egypt," Ain Shams Eng. J., vol. 11, no. 4, pp. 1001-1011, 2020, doi: 10.1016/j.asej.2020.02.003.

[17] J. Preston, "The Economics of Investment in High Speed Rail Discussion Paper 2013 - 30 The Economics of Investment in High Speed Rail Summary and conclusions," 2013,

[18] C. Nash, "When to invest in high speed rail," J. Rail Transp. Plan. Manag., vol. 5, no. 1, pp. 12-22, 2015, doi: 10.1016/j.jrtpm.2015.02.001.

[19] P. Beria, R. Grimaldi, D. Albalate, and G. Bel, "Delusions of success: Costs and demand of high-speed rail in Italy and Spain," Transp. Policy, vol. 68, no. September 2017, pp. 63-79, 2018, doi: 10.1016/j.tranpol.2018.03.011.

[20] D. Albalate and G. Bel, "High-Speed Rail: Lessons for Policy Makers from Experiences Abroad," Public Adm. Rev., vol. 72, no. 3, pp. 336-349, 2012, doi: 10.1111/j.1540-6210.2011.02492.x.

[21] E. Pastori et al., "Research for TRAN Committee Modal shift in European transport: a way forward," no. November, 2018.

[22] R. Vickerman, "High-speed rail and regional development: The case of intermediate stations," $J$. Transp. Geogr., vol. 42, pp. 157-165, 2015, doi: 10.1016/j.jtrangeo.2014.06.008.

[23] R. Vickerman, "High-speed rail in Europe: Experience and issues for future development," Ann. Reg. Sci., vol. 31, no. 1, pp. 21-38, 1997, doi: $10.1007 / \mathrm{s} 001680050037$.

[24] T. Wang, "Effects of high-speed rail on regional development," Degree Proj. Urban Reg. Planning, Adv. Cycle Stock. Sweden 2015, 2015.

[25] J. M. Carbo, D. J. Graham, Anupriya, D. Casas, and P. C. Melo, "Evaluating the causal economic impacts of transport investments: evidence from the MadridBarcelona high speed rail corridor," J. Appl. Stat., vol. 46, no. 9, pp. 1714-1723, Jul. 2019, doi: 10.1080/02664763.2018.1558188.

[26] B. Rutzen and C. M. Walton, "High Speed Rail: A Study of International Best Practices and Identification of Opportunities in the U.S. 7.," vol. 7, no. 2, 2011.

[27] J. Eliasson, "A cost-benefit analysis of the Stockholm congestion charging system," Transp. Res. Part A Policy Pract., vol. 43, no. 4, pp. 468-480, 2009, doi: 10.1016/j.tra.2008.11.014.

[28] D. Hoyos and G. Bueno, "8 Environmental assessment of," no. August, 2016. 